\title{
Climate change adaptation and food production in Canada: some research challenges
}

\author{
S. Kulshreshtha ${ }^{1} \&$ E. Wheaton ${ }^{2}$ \\ ${ }^{1}$ Bioresource Policy, Business and Economics, \\ University of Saskatchewan, Canada \\ ${ }^{2}$ Saskatchewan Research Council, Canada
}

\begin{abstract}
Canada is a vast country and faces different types of weather and climatic patterns. As a result, Canadian agriculture is a spatially heterogeneous industry and therefore, would face differing impacts of climate change in different regions. Depending on the region of study, although, such impacts would vary with different climate characteristics, differing enterprise combinations and the adaptation potential of producers may also have a significant role to play. In general, as average temperatures increase in northern latitudes, for many crops particularly in the northern regions of Canada (more specifically in the Prairie region); such impacts are estimated to be positive for the shorter term through higher yields. New production opportunities are expected to emerge; however, such knowledge is somewhat scarce. These positive benefits of climate change would be reduced when extreme events strike - droughts and floods are expected to become more frequent and severe. Although the impacts of one-year or backto-back droughts have been estimated, such is not the case with the impact longer period drought might have on producers and the economic system in Canada. For livestock, due to a negative impact on forage, pastures, and feed grain production, coupled with higher temperatures, some livestock productivity is expected to suffer in some regions. However, empirical studies on this impact are lacking. Among various challenges in meeting knowledge gaps some stand out. For example, many studies have employed different methodologies with respect to assumption of level of climate change, prediction period, inclusion of $\mathrm{CO}_{2}$ fertilization effect, shift of agro-ecosystems northwards, inclusion or exclusion of extreme events, among others. This makes comparison of regional
\end{abstract}


impacts difficult. Another major gap is in terms of identifying the exact nature of new opportunities that would be created by the changing climate. As Canadian agriculture depends heavily on exports of commodities, the industry would be affected not only by the impacts of climate change locally but also those elsewhere in the globe. A systematic study of identifying future markets for Canadian agricultural products is needed. In terms of adaptation, conversion of dryland agriculture to irrigation is suggested to be a common recommendation. However, due to the fact that climate change would also affect water availability as glaciers retreat (affecting water availability on the Prairies), and aquifers have lower yields, the potential for such adaptations would be low and expensive. Climate change would also require knowledge of adaptation measures that can be undertaken over the short to long term. Such knowledge is also very scarce. Keywords: Canada, agriculture, climate change, adaptation, extreme events.

\section{Introduction}

Agriculture in Canada is an important industry, particularly in several provinces. In 2010, the industry was estimated to have produced products over $\$ 41$ billion through crop and livestock products. Although for the nation as a whole, crop production is valued at half of the total value of agricultural production in some provinces, such Saskatchewan, Manitoba, Ontario and Prince Edward Island, and Manitoba, the share of crop production is even higher than the national average.

Although agriculture is a vital component of the Canadian economy, only a small proportion of land is actually farmed. Due to limitations imposed by climate and soils, just $7 \%$ of the Canada's landmass is used for agricultural purposes [1]. Climate is an important factor determining not only the geographical limits to agricultural production, but also year to year variability in crop yields, productivity of livestock enterprises, and through these ultimately its economic position.

The primary objective of this paper is to review the current state of knowledge of the impacts of climate change on Canadian agriculture. Based on this review, gaps in knowledge related to impacts of climate change and adaptation measures are identified.

The paper is organized in six sections: Section 2 includes a general description of impacts of climate change, followed by evidence of expected impacts on crop and livestock production. In Section 4 a review of adaptation its need and options are described. Section 5 gives an overview of additional research needs, followed by conclusions.

\section{Climate change characteristics relevant to agriculture}

\subsection{Sources of impacts}

In general, climate change aspects relevant to agriculture include mainly three changes: increased temperatures particularly in the higher latitudes; slightly higher and more variable precipitation, and higher frequency of extreme events 
(e.g., droughts and floods). Several impacts on the Canadian agriculture, would result, some favourable, while others are not so favourable (Figure 1). Major changes are expected to occur through three paths: 1. direct climate induced changes; 2. indirect changes through hydrological changes; and 3. climateinduced changes in the rest of the world. The last set of changes is of major significance to Canada since much of the agricultural production for major grains and oilseeds is destined to exports.

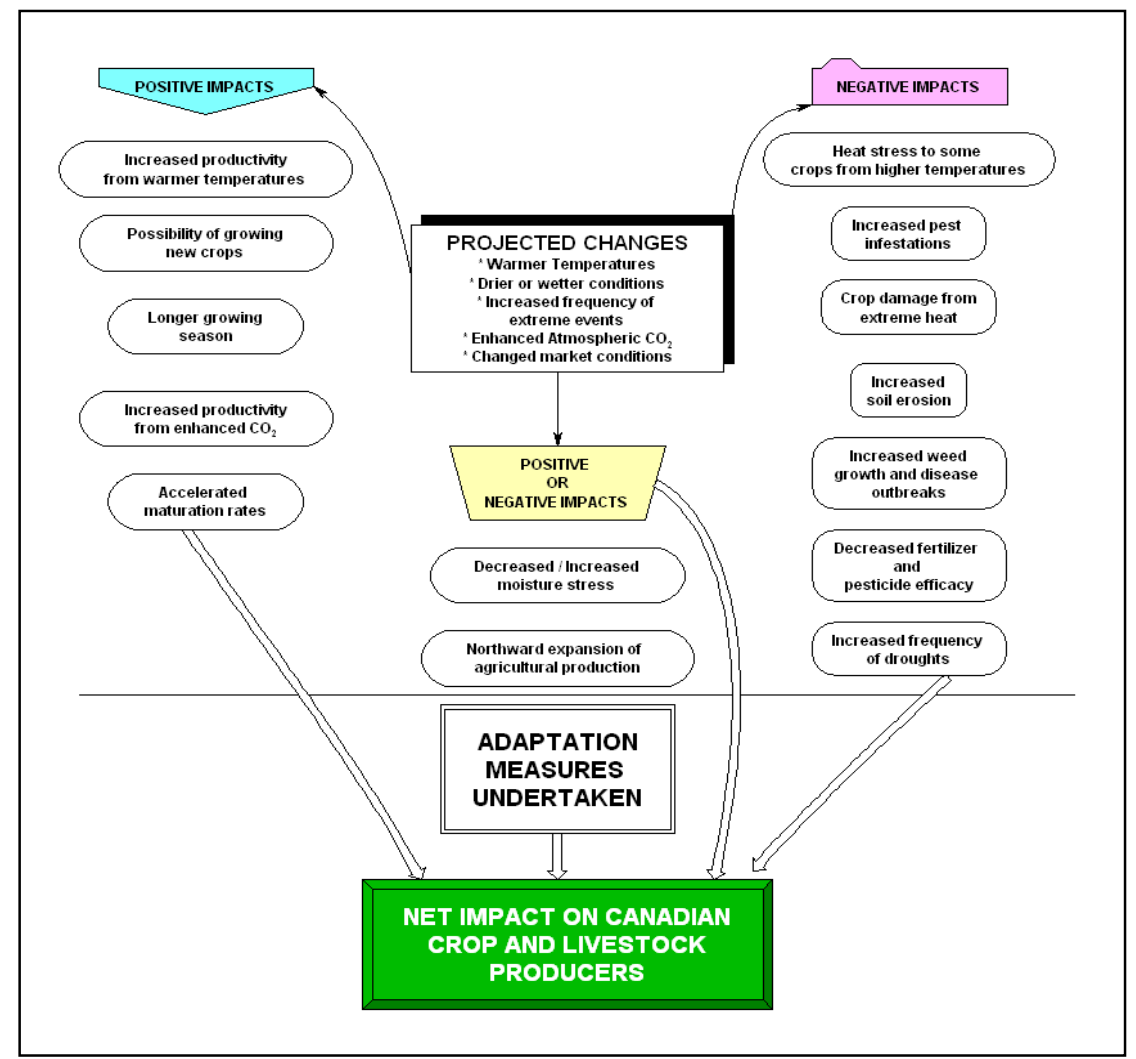

Figure 1: Sources of climate change induced impacts on Canadian agriculture. (Note: accelerated maturation rates can also (although perhaps more frequently) result in lower yields. It would only be positive if it acts to avoid the summer drought and heat. It could easily belong to the positive/negative area.)

Past studies of climate change suggest that all of Canada, with the possible exception of the Atlantic off-shore region, is projected to warm during the next decades. In most cases, future changes in climate will involve a continuation of the patterns, often an acceleration of the past trends, and possibly new patterns. However, the amounts of warming will not be uniform across the country. Some 
regions such as the Prairie Provinces are expected to warm more than the rest of the country with warming accentuated during the fall and winter, particularly in the northern latitudes.

Future precipitation is more difficult to project than temperature because of its greater variability. However, annual total precipitation is projected to increase across the country during the current century. By the 2080s, projected precipitation increases range from 0 to $10 \%$ in the far south up to 40 to $50 \%$ in the high Arctic. There is also some evidence that under climate change precipitation would be more concentrated in fewer days, thus increasing the risk of flooding and crop and infrastructure damage. Precipitation events in 2010 in the Canadian prairies are witness of this impact, where several thousand acres of crop land could not he seeded due to high moisture.

Due to enhanced evapotranspiration driven by higher temperatures, many regions will experience a moisture deficit despite higher amounts of precipitation. Some of the most significant and pervasive impacts in the Prairies as well as for whole of Canada will be related to water resources - precipitation, its distribution, and soil moisture. Water stress during critical times for plants (e.g., germination and flowering) is especially harmful.

Climate change may also bring opportunities, including longer and warmer growing seasons, which could increase productivity and allow cultivation of new and potentially more profitable crops and tree species.

\section{Expected impacts of climate change}

Climate change would include impacts on all types of enterprises and in all regions of Canada. Those effects on crop and livestock production are described below.

\subsection{Crop production}

The crop production systems are susceptible to changes in disturbance regimes, such as more frequent drought. The cumulative nature of impacts, and associated cascading uncertainties, makes it likely that climate change will produce 'surprises' - impacts related to the crossing of critical thresholds that have not been anticipated.

The available evidence on the impacts of climate change on crop yields in various regions of Canada suggested a high degree of uncertainty. Results indicate an increase as well as a decrease in crop yields for various crop types in different regions (Table 1). In general, evidence suggests a moderate increase in crop yields (Arthur [2]) under various climate change scenarios for the shorter term; however, for Saskatchewan Wang et al. [3, 4] have warned about heat stress in crops which may result in yield losses.

Extreme events can have devastating impacts on crop yields. As shown in Figure 2, several severe droughts have been experienced in various parts of Canada. Each of these droughts have has devastating impacts on the Canadian economy. For example, during the 2001-2002 drought, yields of various crops 
were as little as half or less of average yields [7]. If drought frequency increases under climate change, as projected, yields of various crops would decrease, thereby increasing the vulnerability of producers. Increasing water scarcity is one of the most serious risks for agriculture and society [8].

Table 1: Change in the yield of selected crops (\% from current) under climate change [5].

\begin{tabular}{|l|c|c|c|c|c|c|}
\hline \multicolumn{1}{|c|}{ Crop } & $\begin{array}{c}\text { BC/Lower } \\
\text { mainland }\end{array}$ & Peace River & Prairies & Ontario & Quebec & $\begin{array}{c}\text { Atlantic } \\
\text { Canada }\end{array}$ \\
\hline Small Grains & 0 to $-45 \%$ & -46 to $+18 \%$ & -48 to $+18 \%$ & -28 to $+11 \%$ & -15 to $+40 \%$ & $-17 \%$ \\
\hline Coarse Grains & -73 to $+10 \%$ & & & -31 to $+4 \%$ & -7 to $+45 \%$ & \\
\hline Oilseeds & -58 to $0 \%$ & -39 to $+13 \%$ & -50 to $+25 \%$ & -31 to $+11 \%$ & -21 to $+49 \%$ & -24 to $0 \%$ \\
\hline Forages & -43 to $+3 \%$ & -39 to $+2 \%$ & -43 to $+19 \%$ & -13 to $+3 \%$ & & -8 to $-4 \%$ \\
\hline Potato & -50 to $0 \%$ & -25 to $+23 \%$ & -45 to $+24 \%$ & -29 to $+25 \%$ & & -15 to $-5 \%$ \\
\hline
\end{tabular}

Although some beneficial changes may exist (such as a higher level of pulse production, increase in the area under cultivation, and its productivity), if the rates of change are faster than producers have experienced, they may pose more difficulties for adaptation. For example, production of new crops may become agronomically feasible, but whether producers would be able to adapt sufficiently or quickly enough to these new realities is somewhat uncertain. Financial, learning and other requirements for making such adaptations may be major constraints.

Since Canada is an exporter of agricultural commodities, particularly grains and oilseeds, international markets will play an important role in determining the economic impact of climate change on the Canadian agricultural sector. As most of the crops are sold in the international market place, their prices would be significantly influenced by conditions not only within Canada but also in the rest of the world. With respect to the market supply-demand conditions, a review by Kulshreshtha et al. [9] has suggested: (i) For US agriculture, most crops would show gains in crop yields to certain thresholds of temperature increase, which may increase their potential for exports. (ii) For Australia, predicted outcomes from climate change are different, where a reduction is predicted. This would somewhat reduce Canada's competition in some cereal export markets, notably wheat. (iii) European countries are also expected to have a decrease in production, although results may vary from country to country. (iv) On the developing countries' scene, the consensus seems to be a decrease in the potential production, particularly in African countries.

Overall to feed over 9 billion people by 2050, world food production has to increase substantially. IIASA [10] has estimated a deficit of 10 to 250 million tonnes of food products by 2080. Given that demand in many of these countries, caused primarily by population growth, would most likely increase, the potential for Canada to export more would likely exist. However, there exists a need for a country by country assessment of Canada's potential for exports in crop products. Furthermore, since a part of the variability may be in the assumptions made by each researcher, this suggests the need for a comparable analysis of climate change and impacts under a similar set of assumptions and models. 


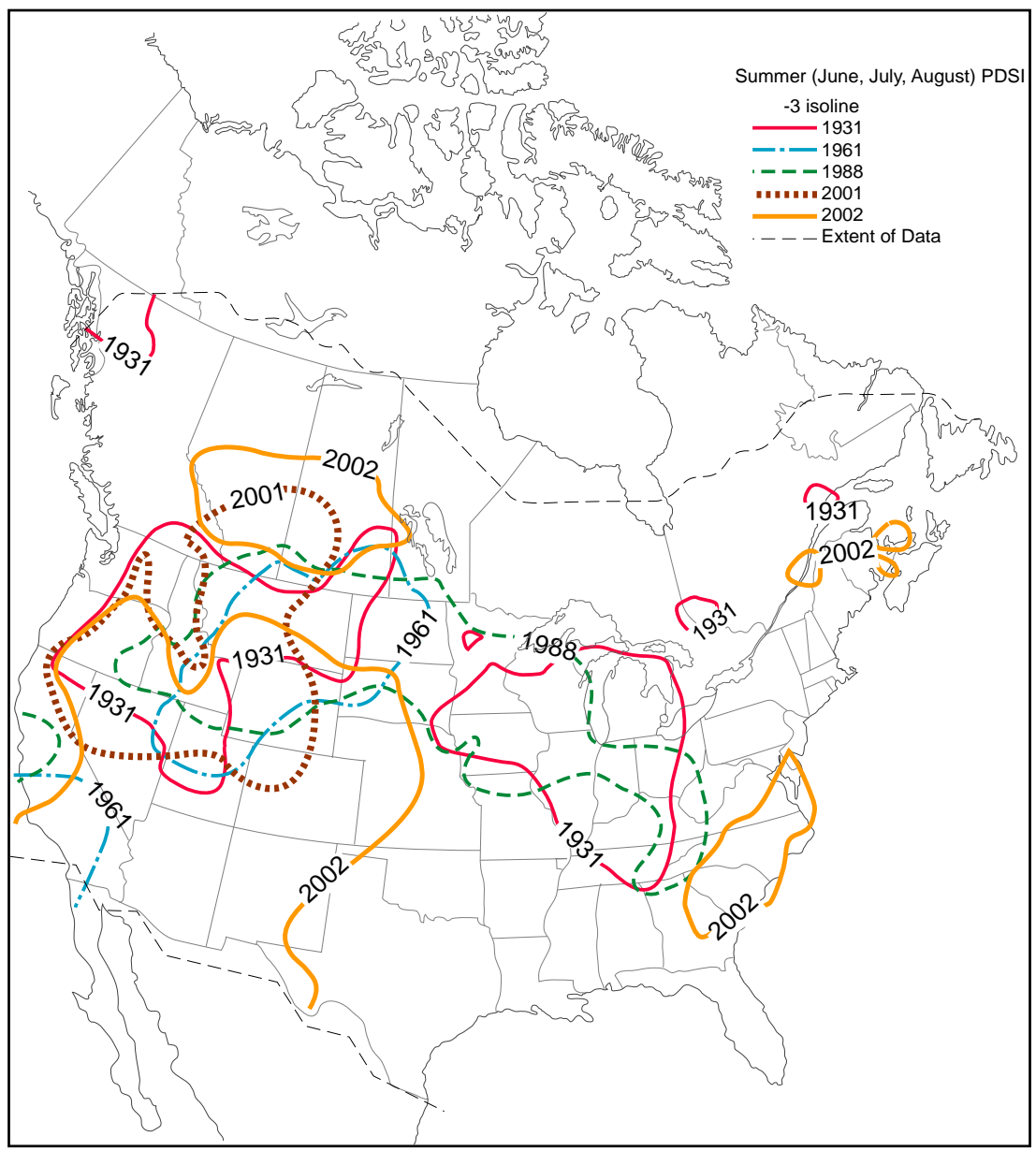

Figure 2: $\quad$ Past drought events in Canada [6].

\subsection{Livestock production}

The impact of climate change on livestock production is a relatively unstudied subject in Canada, as well as in many other countries in the world. Conceptually, major benefits would result through higher winter temperatures (lowering feed requirements), increased survival of the young, and reduced energy costs. However, Baumgard et al. [11] has suggested that climate change heat stress will both directly and indirectly influence animal welfare and productivity.

Another indirect effect of the changing climate on livestock production is through pasture production. Pasture capacity is one of the major factors affecting economics of beef cattle production. Parton et al. [12] have predicted a decrease in soil organic matter, in colder regions due to increased decomposition, which 
may affect pasture carrying capacity. Such findings have been supported by Thorpe et al. [13].

\section{Need for adaptation}

The most important consequence of the past research on climate change is the realization that the combined effects of many small and unrelated activities can have substantial effects on society. These effects are not transitory, and will last for many years into the future, even if drastic measures are adopted now to reverse the negative impacts of climate change.

\subsection{What is adaptation?}

Adaptation practices refer to actual adjustments, or changes in decision environments, which might ultimately enhance resilience or reduce vulnerability to observed or expected change in climate. Most adaptation options, according to Smit and Skinner [14] are modifications to on-going farm practices and public policy decision-making processes with respect to a suite of changing climatic (including variability and extremes) and non-climatic conditions (political, economic, and social). Adaptation has been categorized in many ways by several authors (e.g. Smit and Skinner [14] and Wheaton and MacIver [15]).

\subsection{Stages in adaptation process}

There are three stages in the adaptation of agriculture to a change in climate (Mount [16]). The first stage is to determine whether new measures (such as cultivars, crops, and management practices) can be developed that are better suited to new conditions. The second stage is whether farmers would adopt the new measures if developed. In a market economy, such as the one faced by crop producers in Canada, this is governed by market forces. The new measure is attractive to producers if it leads to positive gains, measured in terms of farm net income and if it is practical. The third stage in the adaptation is the response of markets to changes in supply. Farmers' decisions to adopt (or not to adopt) certain crops or management practices may have a significant effect on the market supply.

\subsection{Operationalizing adaptation}

Adaptation to climate change may be facilitated by two sets of actions: One, measures undertaken by various institutions and individuals to strengthen adaptive capacity of producers to climate change; and two, delivering of adaptation actions.

Building adaptive capacity includes measures to create information and conditions (regulatory, institutional, and managerial) that are needed to support adaptation (Stern [17]). These measures may include understanding the potential impacts of climate change, identification of options for adaptation (i.e., undertaking impact studies and identifying vulnerabilities), piloting specific 
actions and accumulating the resources necessary to implement actions. In the context of droughts, Marchildon et al. [18] concluded that the severe and large area droughts, such as in 1988 and 2001-2002, would likely have been much worse without the institutional adaptations and lessons learned from earlier droughts. Wheaton and Kulshreshtha [19] also stress that institutional adaptations will be required to proactively deal with impacts of climate change on agriculture. Existing policies and programs may not be adequate to meet the challenges and may need to be considerably modified. Problems with other policies may also have interactions with policies to deal with climate change. A re-examination of current policies is needed in light of climate change.

Delivering adaptation measures involves taking steps that will help to reduce vulnerability to climate risks or to exploit opportunities (Stern [17]). These examples include planting of different crops, altering timing of crop planting, taking off-farm income, and investing in physical infrastructure to protect against specific climate risks, such as flood control measures, or new reservoirs and other capacities for irrigation. Farmers are considered to be highly adaptable. They have adapted to the past changes in economic and climatic conditions by expanding and diversifying their operations and increasing efficiency.

Although the literature is full of suggested adaptation practices, what is missing is knowledge of which of these measures would work the best under Canadian condition with climate change effects in place.

\subsection{Barriers and limits to adaptation}

In most cases, including crop producers in Canada, market forces are unlikely to lead to efficient adaptation (Stern [17]). Financial constraint of producers may be one aspect that can be addressed through proper policy measures, as adaptive capacity is lower for farmers with lower incomes.

A wide gap exists between recommended options and those actually implemented. Using the 2001-2002 drought as a case study, Wittrock and Wheaton [20] compared recommended or potential options with actual options used as another way of evaluating the effectiveness of adaptation. The differences between potential and actual adaptation indicates the room for improvement of the actual adaptation process or adaptation deficit. The coping range of the agricultural sector and society was found to be frequently exceeded because of the many devastating and costly impacts that were beyond the ability of current adaptation actions. This means that further adaptation research, planning, capacity building, and implementation require urgent attention and support.

\section{Additional research needs}

Research needs in the area of climate change impacts and adaptation could include a number of topics. Examples of direct impact on crop production include: (1) Most studies reviewed by Kulshreshtha et al. [9] have taken into account the effect of a change in temperature and total precipitation. No study 
was found that had included change in the distribution of precipitation or in the form of precipitation (snow vs. rain). Other changes induced by climate change, such as pollination, heat stress days, asymmetry in day and night temperatures, among others, were also not included. The incorporation of drought and flood frequency is also missing. (2) Much of the past research has concentrated on cereals and to a limited extent on oilseeds (mainly canola). Research on other oilseeds, forages, and potatoes has been less extensive. Fewer studies were found that examined the impact of climate change on fruits and vegetables. (3) None of the studies reviewed here indicated any new crops that would grow under new climate change regimes. (4) One of the important gaps in the information is that in projecting future trend in crop yields is that the interaction of climate changes and enhanced $\mathrm{CO}_{2}$ concentrations with other environmental stresses, such as ozone and UV-radiation. (5) Many of the past studies have used a simulation approach to predict crop production, and beneficial effect of adoption of adaptation measures. Although these studies have shown the potential of measures to offset negative effects on agriculture, often they make very positive assumptions about the capability to find and use the new technology and its effectiveness. (6) A wide variability in crop yields demonstrates that the optimal fit for different pulse crops in the northern Great Plains is not well known and is a research gap. A study of pulse production in various parts of Canada under future climate may provide significant insights into adaptation to climate change.

The topics related to adaptation include: (7) For purposes of implementing adaptations to climate change in agriculture, there is a need to better understand the relationship between potential adaptation options and existing farm-level and government decision-making processes and risk management framework. (8) The relationships that determine technology development necessary for making successful adaptation remain unclear. Further investigation of these would lead to a significant pay-off in terms of adaptation to climate change. (9) Although a number of adaptation measures are available, the assessment of their relative efficiency and effectiveness in various Canadian regions under climate change has yet to be undertaken. A comprehensive study of such measures for various regions of Canada would provide insights for future program development for adaptation to climate change. (10) Although irrigation has been noted as an effective adaptation measure to climate change, no study was found that has addressed this issue. Furthermore, in most parts of the world, and more so in western Canada, studies have suggested that there will be insufficient water for agriculture in the coming decades, due primarily to increased non-agricultural uses, and reduced inflow of water into water bodies. This will have significant implications for adaptation strategies and policies for agricultural production and water management.

In addition, lack of integration is also a subject that deserves further inquiry. These may include: (11) Interdependence between crop production and livestock production was not addressed. Livestock production is a significant part of farm income in many Canadian provinces. This type of integrated study is necessary and should be undertaken. (12) An integrated bio-physical-socio-economic assessment of climate change impacts is needed for all regions of Canada. The 
scope of this investigation needs to be national, regional, and international in nature since all these factors would shape the nature of impacts under the changed climate, and the adaptation measures that would be effective in the future. Since no study was found on impact of climate change on interprovincial trade in Canada, this should be a part of this comprehensive assessment. (13) On the international aspect of climate change impacts, no study was found that has reported implications of these changes in production and demand in various parts of the world on Canadian trade flows. Neither has there been an assessment of impacts of these changes for the exports of agricultural products from the Canadian regions. (14) The estimation of socio-economic impacts of extreme events in various regions of Canada is also a topic that has not received much attention in the Canadian literature. Such a study is also needed using a comparable methodology. (15) Another aspect of climate change research is vulnerability of agricultural communities from these changes. Producers' and communities' vulnerability to hazards, such as a drought, need to be assessed in a comprehensive manner. (16) The strong role for the governments will require institutional reform and capacity-building, at both national and global levels. The exact nature of such reforms needs further research.

Although the above list is not exhaustive, it may serve well for future researchers.

\section{Summary and conclusions}

Current and future climatic challenges faced by agricultural producers are numerous and require many difficult adaptations, especially when compounded by other non-climatic changes, such as markets. Although accumulated climate conditions, such as growing degree-days, are important for achieving stages of crops and insects, extremes often cause the most havoc. Facing such conditions in the future, a number of adaptation measures have been suggested, as adaptation is crucial to deal with the unavoidable impacts of climate change in Canada, and in particular for the agriculture industry. However, adaptation can only mute the impacts; it cannot by itself solve the problem of climate change. At the same time, there are limits to what adaptation can achieve, since as the speed of climate change increases and effects accumulate and worsen, the relative effectiveness of adaptation will diminish. Furthermore, as Polsky and Easterling [21] have noted that a country's climate sensitivity is influenced not only by its climate but also by social factors associated with the agro-climatic zone in which it is located.

Estimates of climate change impacts on crop production are wide-ranging and uncertain and depend on many assumptions, including those for farm-level adaptation. Even with some beneficial changes, if the rates of change are faster than producers have experienced, they may pose more difficulties for adaptation. The speed of change is important and a faster rate than previous means a more rapid rate of adaptation is needed, including policies to help deal with climate change impacts. 


\section{References}

[1] Warren, Fiona J. Agriculture, in D. S. Lemmen and F. J. Warren (eds.). Climate Change Impacts and Adaptation: A Canadian Perspective. Prepared by the Climate Change Impacts and Adaptation Directorate, Ottawa: Natural Resources Canada, 2004.

[2] Arthur, L. M. "Socio-Economics Impact of Climate Change on Prairie Agriculture: The Greenhouse Effect." In B. L. Magill and F. Geddes (eds.). The Impact of Climate Variability and Change on the Canadian Prairies Proceedings of the Symposium/Workshop. Edmonton: Alberta Environment, 1988.

[3] Wang, H, Y. He, B. Qianm, B. McConkey, H. Cutforth, T. McCaig, G. McLeod, R. Zentner, C. Campbell, R. DePauw, R. Lemke, K. Brandt, T. Liu, X. Qin, G. Hoogenboom, and T. Hunt. Impact of Climate Change on Wheat Production for Ethanol in Southern Saskatchewan, Canada. World Renewable Energy Congress 2011-Sweden, 8-13 May 2011, Linkoping, Sweden, 2011.

[4] Wang, H., R. Lemke, T. Goddard, C. Sprout. Tillage and root heat stress in wheat in Central Alberta, Canadian Journal of Soil Science 87, pp. 3-10, 2007.

[5] Brklacich, M., C. Bryant, B. Veenhof and A. Beauchesne. "Implications of Global Climatic Change for Canadian Agriculture: A Review and Appraisal of Research from 1984 to 1997." In G. Koshida and W. Avis (eds.). The Country Canada Study: Climate Impacts and Adaptation - National Sectoral Volume. Ottawa: Environment Canada, 1988.

[6] Wheaton, E. with V. Wittrock, S. Kulshreshtha, G. Koshida, C. Grant, A. Chipanshi, and B. Bonsal. Lessons Learned from the Canadian Droughts Years of 2001 and 2002: Synthesis Report.SRC Publication No. 1160246E03. Saskatoon, SK: Saskatchewan Research Council, 2005.

[7] Wheaton, E., S. N. Kulshreshtha, V. Wittrock and G. Koshida. Dry times: hard lessons from the Canadian drought of 2001 and 2002. Canadian Geographer. 52(2), pp. 241-262, 2008.

[8] Sauchyn, Dave; E. Barrow, X. Fang, N. Henderson, M. Johnston, J. Pomeroy, J. Thorpe, E. Wheaton, and B. Williams. Saskatchewan's Natural Capital in a Changing Climate: An Assessment of Impacts and Adaptation. Report to Saskatchewan Ministry of Environment from the Prairie Adaptation Research Collaborative, 167 pp, 2009.

[9] Kulshreshtha, S., E. Wheaton, A. Amiraslany, H. Hill, A. Chipanshi, and A. Howard. A Literature Survey of Potential Socio-Economic Impacts of Climate Change on Canadian Crop Production. University of Saskatchewan Report. Saskatoon: University of Saskatchewan.74 pp, 2010.

[10] IIASA (International Institute for Applied Systems Analysis). Biofuels and climate change: Challenge to food security in the twenty-first century. Options. Winter, pp. 18-9. Laxenburg, Austria, 2009/10.

[11] Baumgard, L. H., Robert P. Rhoads, Michelle L. Rhoads, Nicholas K. Gabler, Jason W. Ross, Aileen F. Keating, Rebbeca L. Boddicker, Sangeeta 
Lenka and Veerasamy Seji. Impact of Climate Change on Livestock Production. Chapter 15. In V. Sejian et al. (eds.), Environmental Stress and Amelioration in Livestock Production, DOI: 10.1007/978-3-642-292057_15, 2012.

[12] Parton, W. J., J. M. O. Scurlock, D. S. Ojima, D. S. Schimel, D. O. Hall and Scopegram Group Members. Impact of Climate Change on Grassland Production and Soil Carbon Worldwide. Global Change Biology 1, pp. 13$22,1995$.

[13] Thorpe, J., B. Houston, and S. Wolfe. Impacts of Climate Change on Grazing Capacity of Native Grasslands in the Canadian Prairies. Saskatoon, Saskatchewan: Saskatchewan Research Council, 2004.

[14] Smit, B. and M. Skinner. Adaptation Options in Agriculture to Climate Change: a Typology. Mitigation and Adaptation Strategies for Global Change 7, pp. 85-114, 2002.

[15] Wheaton, E. E. and D. C. MacIver. A Framework and Key Questions for Adapting to Climate Variability and Change. Mitigation and Adaptation Strategies for Global Change 4, pp. 215-225, 1999.

[16] Mount, T. D., Climate Change, Sustainable Economic Systems and Welfare. Brock Review. 2(1), pp. 2-21, 1993.

[17] Stern, N. The Economics of Climate Change - The Stern Review. New York: Cambridge University Press, 2007.

[18] Marchildon, G. P., S. Kulshreshtha, E. Wheaton, and D. Sauchyn. Drought and Institutional Adaptation in the Great Plains of Alberta and Saskatchewan, 1914-1939. Natural Hazards, 45, pp. 391-412, 2008.

[19] Wheaton, E. and S. Kulshreshtha. Agriculture, in D. Sauchyn, H. Diaz and S. Kulshreshtha (eds). Climate Change in the Prairies: The New Normal. Regina: The Canadian Prairie Research Center Press, 2010.

[20] Wittrock, V. and E. Wheaton. Towards Understanding the Adaptation Process for Drought in the Canadian Prairie Provinces: The Case of the 2001 to 2002 Drought and Agriculture. Prepared for the Government of Canada, Climate Change Impacts and Adaptations Program. SRC Publication No. 11927-2E07.Saskatchewan Research Council, Saskatoon, Saskatchewan, 130 pp, 2007.

[21] Polsky, C. and W. E., Easterling. Adaptation to climate variability and change in the US Great Plains: A multi-scale analysis of Ricardian climate sensitivities. Agriculture, Ecosystems and Environment 85, pp. 133-144, 2001. 